\title{
Association between social health status and health-related quality of life among community-dwelling elderly in Zhejiang
}

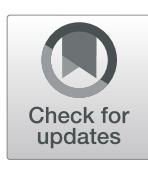

Jieming $\mathrm{Lu}^{1 \dagger}$, Zhebin $\mathrm{Yu}^{1 \dagger}$, Xiaocong Zhang ${ }^{1}$, Mengyin $\mathrm{Wu}^{1}$, Shujuan Lin ${ }^{1}$, Yao Zhu', Zenghao Xu', Liuqing You', Fang Wei ${ }^{1}$, Mengling Tang ${ }^{1}$, Mingjuan $\mathrm{Jin}^{2}$, Jianbing Wang ${ }^{3^{*}}$ and Kun Chen ${ }^{2^{*}}$

\begin{abstract}
Background: Population aging is an inevitable trend and previous studies have showed the relationship between social health related factors and health-related quality of life (HR-QOL) in the elderly. The objective of this study is to investigate the association of social health status with HR-QOL among community-dwelling elderly in Zhejiang.

Methods: This cross-sectional study was based on community-dwelling elderly individuals from July 2018 to September 2018 in Zhejiang, China. HR-QOL was measured by the 12-item Short-Form Health Survey (SF-12). Social health status was estimated by the long-form of the Social Health Scale for the Elderly (SHSE-L) and classified into three categories (poor, moderate and good). Multivariable linear regression models were conducted to evaluate the association between social health status and HR-QOL (PCS, MCS and SF-12 total score).

Results: A total of 2952 elderly participants were included in this study. The mean age was $70.68 \pm 7.75$ years (mean \pm SD); of the eligible participants, more than half (50.4\%) were females; the mean scores were $48.10 \pm 8.49$, $47.70 \pm 7.09$ and $47.90 \pm 5.86$ for PCS, MCS and SF-12 total score, separately. Results from the multivariable models showed that social health status was positively related to HR-QOL after adjusting for covariates. Compared with individuals with a poor social health status, those who had a moderate or good social health status were more likely to report better HR-QOL (for moderate social health status: $\beta=1.90(95 \% \mathrm{Cl}: 1.09,2.71$ ) for PCS, $\beta=1.78(1.08$, 2.48) for MCS, $\beta=1.84(1.29,2.39)$ for SF-12 total score; for good social health status: $\beta=3.29(2.24,4.34)$ for $P C S, \beta=$ $3.10(2.12,4.01)$ for MCS, $\beta=3.20(2.48,3.91)$ for SF-12 total score).

Conclusion: In our study, we found that social health status was positively associated with HR-QOL among the elderly in Zhejiang. Our findings could provide valuable information for decision-makers to develop interventions to improve the HR-QOL of the elderly.
\end{abstract}

Keywords: Social health, Health-related quality of life, Older people

\footnotetext{
* Correspondence: wangjianbing@zju.edu.cn; ck@zju.edu.cn

${ }^{\dagger}$ Jieming Lu and Zhebin Yu contributed equally to this work.

${ }^{3}$ Department of Epidemiology and Biostatistics, the Children's Hospital,

National Clinical Research Center for Child Health, Zhejiang University School

of Medicine, Hangzhou, China

${ }^{2}$ Department of Epidemiology and Biostatistics, Cancer Institute, the Second Affiliated Hospital, Zhejiang University School of Medicine, Hangzhou, China

Full list of author information is available at the end of the article
}

(c) The Author(s). 2020 Open Access This article is licensed under a Creative Commons Attribution 4.0 International License, which permits use, sharing, adaptation, distribution and reproduction in any medium or format, as long as you give appropriate credit to the original author(s) and the source, provide a link to the Creative Commons licence, and indicate if changes were made. The images or other third party material in this article are included in the article's Creative Commons licence, unless indicated otherwise in a credit line to the material. If material is not included in the article's Creative Commons licence and your intended use is not permitted by statutory regulation or exceeds the permitted use, you will need to obtain permission directly from the copyright holder. To view a copy of this licence, visit http://creativecommons.org/licenses/by/4.0/ The Creative Commons Public Domain Dedication waiver (http://creativecommons.org/publicdomain/zero/1.0/) applies to the data made available in this article, unless otherwise stated in a credit line to the data. 


\section{Background}

With the development of the economy and modern medical techniques, population aging is an inevitable trend. World health organization (WHO) reported that the global population of older people aged 60 years or older reached 0.9 billion in 2015 and may grow further into nearly 2 billion by 2050 [1]. The 2010 census in China showed that individuals aged 60 years or above accounted for $13.3 \%$ of the total population in 2010, up by $2.9 \%$ as compared with that from the 2000 census [2]. Due to the increasing life expectancy, health-related quality of life (HR-QOL) assessment is considered as a particularly important public health tool for the elderly, which can help determine the burden of preventable disease, injuries, and disabilities [3].

HR-QOL is a common approach to the conceptualization of the broader concept of quality of life (QOL). It has been defined as: "the impact of perceived health on an individual's ability to live a fulfilling life" [4]. Common dimensions of HR-QOL include physical, psychological, and social components, which may compensate for, or depend on each other. The multidimensionality of HR-QOL makes it pertinent to examine both the respective dimensions of the concept but also the overall score for the population of interest [5]. A number of factors have been identified to be related to HR-QOL among the elderly, such as socioeconomic status, lifestyle behaviors, and health conditions [6-11]. However, social health (such as social support and social relationship) may also affect health-related quality of life in the elderly.

Social health is defined as an ability to accomplish potential and obligations, to manage their life to some extent despite a medical condition, and the ability to participate in social activities including work [12]. Social health contains two aspects: individual and society or a population [13]. Social health of an individual is usually explained as "well-being", "adjustment" or other terms rather than health [14], and it can be measured from two aspects: social support (SS) and social adjustment (SA). Social health for a society mainly reflects the neighborhood environment [15]. A number of studies have focused on the association between a single level of social health and HR-QOL among the elderly [16-19]. A study conducted in China found the relationship between social support and HR-QOL, mediating role of resilience [20]; A longitudinal study indicated that consistent participation in religious activities, friendship organizations, leisure/culture clubs, family/school reunion, and volunteer work could improve the quality of life among middle-aged and older Koreans [21]; And a cross-sectional study in Netherlands showed that multiple environmental factors were associated with quality of life in the elderly [22]. However, up to now, limited studies can be available for evaluating the associations of individual and society levels of social health with healthrelated quality of life in the elderly.

Nowadays, a comprehensive structured scale called the Social Health Scale for the Elderly (SHSE) has been developed to fill the gap in social health status measurement [15]. Herein, we reported a cross-sectional study to explore the relationship between social health status and HR-QOL among the elderly in Zhejiang, China.

\section{Method}

\section{Study design and study participants}

Our data were derived from "Development of health assessment instruments and parameter specification for the elderly" project, which has been described in detail previously [15]. Briefly, this was a cross-sectional study based on community-dwelling elderly individuals from July 2018 to September 2018 in Zhejiang, China. Subjects were enrolled from 12 communities of Yiwu county in Jinhua city and Jianggan district in Hangzhou city, Zhejiang. A convenience sampling method stratified by gender and age was used in each community, based on the distribution of age and gender in the elderly population in Zhejiang. Community-dwelling persons aged 60 years and older were recruited in the current study. Individuals were not eligible if they were bed-ridden or could not participate in their daily living activities by themselves due to serious physical disease or had cognitive problems. All participants were informed to be faceto-face interviewed at adjacent community health centers by strictly trained interviewers. This study was approved by the Ethics Committee of School of Medicine, Zhejiang University, Hangzhou, China. Written informed consent was obtained from all participants before the face-to-face interview.

\section{Measurement of social health status}

Social health status was measured through the longform of the SHSE (SHSE-L). The 25-item scale was designed to assess social health status of the elderly (including two aspects: individual and society). Individual dimensions consist of Social Support (including emotional support, information support, and instrumental support), and Social Adjustment (including social participation, social relationships, and ego system); Social dimension is perceived environment resource (including built environment and community manage/service) [15]. Three different scoring methods were used in this study: 1. For multiple option items, scoring was based on the number of selected options; 2. For single option items, scoring was based on the serial number of the single option; 3. For items about passage time, scoring was based on the estimated time and means of transportation. Detailed information and scoring criteria could be available 
in the additional file 1. Crude total score of scale was transformed into standard score ( $\mathrm{T}$ score), based on a previous study performed by Hembling (1984) [23]. T score was divided into three categories of social health status according to standard norm: poor ( $\mathrm{T}$ score $\leq 40$ ), moderate $(40<\mathrm{T}$ score $\leq 60)$, and good $(60<\mathrm{T}$ score $\leq$ 90) [15]. The SHSE-L has been established and validated in the Hangzhou elderly population. The test-retest variability was 0.77 , internal consistency reliability- Cronbach's alpha was 0.79 , concurrent validity was 0.64 , and goodness of fit was 0.95 in construct validity [15].

\section{Measurement of HR-QOL}

We used the 12-item Short-Form Health Survey (SF-12) to evaluate the HR-QOL; SF-12 is a concise questionnaire that evaluates the quality of life in Chinese elderly [24]. The 12 items in SF-12 are grouped into 8 main domains: general health, physical functioning, physical role functioning, bodily pain, vitality, social functioning, emotional role functioning, and mental health. These dimensions can be categorized into the Physical Component Summary (PCS) and the Mental Component Summary (MCS). The PCS was calculated based on the sum of the first four items, and the MCS was determined based on the sum of the last four items [25]. We calculated the scores of PCS, MCS, and SF-12 total score that represented a mean value of the PCS and MCS scores. The detailed calculations of PCS and MCS have been published previously [26], and total score of SF-12 was calculated based on the measurement of SF-36 total score in previous studies [26-28].

\section{Assessment of covariates}

Demographic data were obtained using a standard questionnaire. Three categories of covariates were included in the analyses: socio-demographic characteristics, health-related behaviors, and health conditions. Sociodemographic characteristics included the following variables: region (urban or rural), gender (male or female), age group(60-74 or $\geq 75$ years), marital status (married, widowed or others), education level (lower than primary school, primary school, middle school, or high school and higher), monthly income $(<1000,1000-1999,2000-$ 2999,3000-3999, $\geq 4000$ Chinese Yuan (CNY)), living arrangement (living with spouse, living with children, living with spouse and children, living alone or others), and body mass index (BMI). BMI was calculated as weight in kilograms divided by the square of height in meters and divided into three levels according to the Chinese BMI criteria: $<18.5,18.5-23.9$ or $\geq 24.0 \mathrm{~kg} / \mathrm{m}^{2}$. Health-related behaviors included smoking (yes or no), drinking alcohol (yes or no), drinking tea (yes or no) and weekly physical activity ( $\leq 1$ time, $2-4$ times or $>4$ times). Smokers were defined as individuals who smoked 1 cigarette or more per day for 3 months or more. Alcohol drinkers were defined as individuals who drank one glass of beer, liquor, yellow rice wine or red wine per week for more than 1 year [29]. Tea consumption was defined as drinking at least one cup of tea per day for 1 year. Valid physical activity was defined as at least $15 \mathrm{~min}$ at a time [30]. Health conditions included depression symptom (yes or no) and the number of chronic conditions (none, one, two or more). Depression symptom was measured by the Geriatric Depression Scale (GDS). Chronic conditions were self-reported, including hypertension, coronary heart disease (CHD), diabetes, stroke, osteoporosis, and arthritis.

\section{Statistical analysis}

Continuous and categorical variables were described as mean \pm standard deviation (SD) and $n(\%)$, respectively. T-test and Analysis of Variance (ANOVA) were used to compare the differences in different categories for continuous variables of PCS, MCS and SF-12 total score. We used multivariate linear regression models to estimate beta $(\beta)$ and $95 \%$ confidence intervals $(95 \% \mathrm{CI})$ for examining the associations of social health status with PCS or MCS or SF-12 total score. All models were adjusted for potential covariates. Collinearity was assessed by using the correlation matrix of the estimated parameters, and variance inflation factor (VIF). For all analyses, $P$-value $<0.05$ (two-sided) was considered to be statistically significant. All data were analyzed using the Statistical Package for Social Sciences (SPSS) version 24.0.

\section{Results}

A total of 3161 elderly participants were recruited in our study, and we excluded 15 participants with incorrect information, 81 participants aged < 60 years and 113 participants with incomplete information of SF-12, and a total of 2952 participants were included in the final analysis. The number of poor, moderate and good social health status was 476, 1994, and 482, respectively. The mean scores were $48.10 \pm 8.49$ (mean \pm SD), $47.70 \pm 7.09$ and $47.90 \pm 5.86$ for PCS, MCS and SF-12 total score, separately. Mean age for all participants was $70.68 \pm$ 7.75 years old, and $1487(50.4 \%)$ were females. Approximately $20 \%$ were not married, and less than $20 \%$ had no educational experience. Nearly $50 \%$ of participants lived in the urban regions and half of the participants had less than 2000 yuan per month of income. About $54.4 \%$ of elderly people lived with a spouse, and $49.4 \%$ had a normal BMI (Table 1). A significant difference in PCS was observed across the groups based on social health, gender, age, marital status, education level, monthly income, living arrangement, BMI, smoking, alcohol consumption, tea consumption, weekly physical activity, depression symptom and number of chronic conditions $(P<0.01)$. 
Table 1 HR-QOL according to different groups of demographic characteristics in the Zhejiang elderly

\begin{tabular}{|c|c|c|c|c|c|c|c|}
\hline \multirow[t]{2}{*}{ Variables } & \multirow{2}{*}{$\begin{array}{l}\text { Overall }(n= \\
2952)\end{array}$} & \multicolumn{6}{|l|}{ HR-QOL } \\
\hline & & PCS & $P$ value & MCS & $P$ value & SF-12 total score & $P$ value \\
\hline Social health status & & & $<0.01$ & & $<0.01$ & & $<0.01$ \\
\hline Poor & $476(16.12)$ & $45.07 \pm 9.64$ & & $45.61 \pm 8.23$ & & $45.34 \pm 6.68$ & \\
\hline Moderate & 1994(67.55) & $48.25 \pm 8.34$ & & $47.80 \pm 6.96$ & & $48.02 \pm 5.73$ & \\
\hline Good & $482(16.33)$ & $50.45 \pm 6.89$ & & $49.36 \pm 5.30$ & & $49.91 \pm 4.50$ & \\
\hline Region & & & 0.18 & & $<0.01$ & & $<0.01$ \\
\hline Rural & $1518(51.42)$ & $47.89 \pm 8.20$ & & $46.10 \pm 6.85$ & & $47.00 \pm 5.96$ & \\
\hline Urban & 1434(48.58) & $48.31 \pm 8.78$ & & $49.39 \pm 6.95$ & & $48.85 \pm 5.60$ & \\
\hline Gender & & & $<0.01$ & & $>0.05$ & & $<0.01$ \\
\hline Male & $1464(49.61)$ & $48.94 \pm 8.35$ & & $47.96 \pm 6.70$ & & $48.45 \pm 5.67$ & \\
\hline Female & 1487(50.39) & $47.26 \pm 8.54$ & & $47.45 \pm 7.45$ & & $47.35 \pm 6.00$ & \\
\hline Age group (Years) & & & $<0.01$ & & 0.33 & & $<0.01$ \\
\hline $60-74$ & 2069(70.09) & $49.49 \pm 7.80$ & & $47.78 \pm 6.73$ & & $48.64 \pm 5.40$ & \\
\hline$\geq 75$ & 883(29.91) & $44.84 \pm 9.12$ & & $47.51 \pm 7.88$ & & $46.17 \pm 6.50$ & \\
\hline Marital status & & & $<0.01$ & & $<0.05$ & & $<0.01$ \\
\hline Married & 2370(80.28) & $48.65 \pm 8.27$ & & $47.87 \pm 6.91$ & & $48.26 \pm 5.74$ & \\
\hline Widowed & $491(16.63)$ & $45.33 \pm 9.14$ & & $47.10 \pm 7.86$ & & $46.21 \pm 6.17$ & \\
\hline Others & 91(3.08) & $48.44 \pm 7.65$ & & $46.50 \pm 7.17$ & & $47.48 \pm 5.70$ & \\
\hline Education level & & & $<0.01$ & & $<0.01$ & & $<0.01$ \\
\hline Lower than primary school & $556(19.01)$ & $45.94 \pm 8.68$ & & $46.41 \pm 7.50$ & & $46.18 \pm 6.20$ & \\
\hline Primary school & $953(32.58)$ & $47.78 \pm 8.57$ & & $46.76 \pm 7.03$ & & $47.28 \pm 6.01$ & \\
\hline Middle school & $855(29.23)$ & $49.37 \pm 8.07$ & & $48.56 \pm 6.81$ & & $48.97 \pm 5.40$ & \\
\hline High school or higher & $567(19.38)$ & $48.87 \pm 8.38$ & & $49.23 \pm 6.78$ & & $49.05 \pm 5.40$ & \\
\hline Monthly income (CNY) & & & $<0.01$ & & $<0.01$ & & $<0.01$ \\
\hline$<1000$ & $722(25.38)$ & $47.247 \pm 8.43$ & & $45.74 \pm 7.50$ & & $46.50 \pm 6.32$ & \\
\hline 1000-1999 & $706(24.82)$ & $48.05 \pm 8.45$ & & $47.20 \pm 6.78$ & & $47.62 \pm 6.04$ & \\
\hline 2000-2999 & $570(20.04)$ & $48.49 \pm 8.29$ & & $47.87 \pm 7.48$ & & $48.18 \pm 5.71$ & \\
\hline 3000-3999 & $388(13.64)$ & $47.86 \pm 9.28$ & & $49.44 \pm 6.34$ & & $48.65 \pm 5.45$ & \\
\hline$\geq 4000$ & 459(16.13) & $49.31 \pm 8.31$ & & $50.35 \pm 5.99$ & & $49.83 \pm 4.75$ & \\
\hline Living arrangement & & & $<0.01$ & & $<0.01$ & & $<0.01$ \\
\hline Live with spouse & $1607(54.44)$ & $48.71 \pm 8.20$ & & $48.06 \pm 6.69$ & & $48.39 \pm 5.62$ & \\
\hline Live with children & 296(10.03) & $45.70 \pm 9.01$ & & $46.69 \pm 7.97$ & & $46.19 \pm 6.20$ & \\
\hline Live with spouse and children & $573(19.41)$ & $49.02 \pm 8.21$ & & $48.03 \pm 7.17$ & & $48.52 \pm 5.69$ & \\
\hline Live alone & $322(10.91)$ & $45.65 \pm 8.96$ & & $46.99 \pm 7.39$ & & $46.32 \pm 6.25$ & \\
\hline Others & $154(5.22)$ & $47.95 \pm 8.79$ & & $46.16 \pm 7.94$ & & $47.05 \pm 6.21$ & \\
\hline BMI $\left(\mathrm{kg} / \mathrm{m}^{2}\right)$ & & & $<0.01$ & & $<0.01$ & & $<0.01$ \\
\hline$<18.5$ & 184(6.44) & $45.04 \pm 9.21$ & & $46.81 \pm 8.71$ & & $45.93 \pm 6.66$ & \\
\hline $18.5-23.9$ & $1412(49.42)$ & $48.47 \pm 8.40$ & & $47.38 \pm 7.24$ & & $47.93 \pm 5.87$ & \\
\hline$\geq 24.0$ & $1261(44.14)$ & $48.08 \pm 8.41$ & & $48.21 \pm 6.53$ & & $48.15 \pm 5.62$ & \\
\hline Smoking & & & $<0.01$ & & 0.81 & & $<0.01$ \\
\hline Yes & $388(13.14)$ & $49.73 \pm 8.42$ & & $47.62 \pm 6.62$ & & $48.68 \pm 5.76$ & \\
\hline No & 2543(86.14) & $47.84 \pm 8.48$ & & $47.71 \pm 7.17$ & & $47.78 \pm 5.87$ & \\
\hline Alcohol drinking & & & $<0.01$ & & 0.33 & & $<0.01$ \\
\hline Yes & 558(19.04) & $49.95 \pm 7.73$ & & $47.96 \pm 6.70$ & & $48.96 \pm 5.40$ & \\
\hline
\end{tabular}


Table 1 HR-QOL according to different groups of demographic characteristics in the Zhejiang elderly (Continued)

\begin{tabular}{|c|c|c|c|c|c|c|c|}
\hline \multirow[t]{2}{*}{ Variables } & \multirow{2}{*}{$\begin{array}{l}\text { Overall }(n= \\
2952)\end{array}$} & \multicolumn{6}{|l|}{ HR-QOL } \\
\hline & & PCS & $P$ value & MCS & $P$ value & SF-12 total score & $P$ value \\
\hline No & 2373(80.96) & $47.65 \pm 8.60$ & & $47.64 \pm 7.19$ & & $47.65 \pm 5.94$ & \\
\hline Tea drinking & & & $<0.01$ & & $<0.01$ & & $<0.01$ \\
\hline Yes & $964(32.89)$ & $49.28 \pm 8.22$ & & $48.52 \pm 7.01$ & & $48.90 \pm 5.66$ & \\
\hline No & 1967(67.11) & $47.51 \pm 8.57$ & & $47.30 \pm 7.10$ & & $47.41 \pm 5.90$ & \\
\hline Weekly physical activity & & & $<0.01$ & & $<0.01$ & & $<0.01$ \\
\hline$\leq 1$ time & 1064(37.35) & $46.06 \pm 9.26$ & & $46.39 \pm 7.62$ & & $46.23 \pm 6.47$ & \\
\hline $2-4$ times & $1524(53.49)$ & $49.24 \pm 7.69$ & & $48.90 \pm 6.54$ & & $49.07 \pm 5.08$ & \\
\hline$>4$ times & 261(9.16) & $50.23 \pm 8.00$ & & $47.39 \pm 6.43$ & & $48.81 \pm 5.49$ & \\
\hline Depression symptom & & & $<0.01$ & & $<0.01$ & & $<0.01$ \\
\hline Yes & $767(26.19)$ & $49.09 \pm 7.91$ & & $48.51 \pm 6.25$ & & $48.80 \pm 5.17$ & \\
\hline No & $2162(73.81)$ & $45.43 \pm 9.35$ & & $45.53 \pm 8.66$ & & $45.48 \pm 6.91$ & \\
\hline Number of chronic conditions & & & $<0.01$ & & 0.15 & & $<0.01$ \\
\hline 0 & $777(26.32)$ & $50.56 \pm 7.15$ & & $47.75 \pm 6.29$ & & $49.15 \pm 5.01$ & \\
\hline 1 & 1184(40.11) & $49.00 \pm 7.84$ & & $47.41 \pm 7.23$ & & $48.21 \pm 5.77$ & \\
\hline$\geq 2$ & $991(33.57)$ & $45.08 \pm 9.30$ & & $48.01 \pm 7.50$ & & $46.54 \pm 6.30$ & \\
\hline
\end{tabular}

Similar results were observed for MCS, except for gender, age, smoking, alcohol consumption and number of chronic conditions. For SF-12 total score, there was a significant difference across the groups of all demographic characteristics $(P<0.01)$ (Table 1$)$.

Table 2 summarizes the adjusted association of social health status with HR-QOL. As compared with individuals with a poor social health status, subjects who had a moderate or good social health status were more likely to report better HR-QOL (for moderate social health status: $\beta=1.90(95 \% \mathrm{CI}: 1.09,2.71)$ for PCS; $\beta=1.78(1.08$, $2.48)$ for MCS; $\beta=1.84(1.29,2.39)$ for SF-12 total score; for good social health status: $\beta=3.29(2.24,4.34)$ for PCS; $\beta=3.10(2.20,4.01)$ for MCS; $\beta=3.20(2.48,3.91)$ for SF-12 total score). No collinearity was observed among the variables included in these models.

As for covariates, individuals who were 75 years and older, or had a $\mathrm{BMI}<18.5 \mathrm{~kg} / \mathrm{m}^{2}$ or chronic conditions, or did physical activity less than 2 times weekly, were more likely to report lower PCS. Participants who lived

Table 2 Beta values and 95\% confidence intervals of HR-QOL by social health status in the Zhejiang elderly

\begin{tabular}{llll}
\hline $\begin{array}{l}\text { Social } \\
\text { health }\end{array}$ & PCS & MCS & SF-12 total score \\
status & $\beta(95 \% \mathrm{Cl})$ & $\beta(95 \% \mathrm{Cl})$ & $\beta(95 \% \mathrm{Cl})$ \\
\hline Poor & Ref. & Ref. & Ref. \\
Moderate & $1.90(1.09,2.71)$ & $1.78(1.08,2.48)$ & $1.84(1.29,2.39)$ \\
Good & $3.29(2.24,4.34)$ & $3.10(2.20,4.01)$ & $3.20(2.48,3.91)$ \\
\hline
\end{tabular}

Adjusted for Region, Gender, Age group, Marital status, Education level, Monthly income (CNY), Living arrangement, Smoking, Alcohol drinking, Tea drinking, Depression symptom, Weekly physical activity, BMI level, Number of chronic conditions in urban regions and lived with spouse and children, or had a monthly income over 3000 Yuan or BMI $\geq 24 \mathrm{~kg} /$ $\mathrm{m}^{2}$ or no depression symptom, were more likely to report higher MCS. As for SF-12 total score, subjects who lived in the rural regions, were female or 75 years and older or non-tea drinkers, whose monthly income less than 4000 yuan and BMI $<18.5 \mathrm{~kg} / \mathrm{m}^{2}$, or had chronic conditions with depression symptom were more likely to report lower SF-12 total score (Supplementary Tables S1-3).

\section{Discussion}

This present study aimed at assessing whether social health status was associated with HR-QOL in the Zhejiang elderly. Compared with the elderly with a poor social health status, those who had a better social health status were more likely to report higher scores of PCS, MCS and SF-12 total score, after adjusting for potential covariates. These findings suggest that social health status may be considered as a comprehensive indicator of HR-QOL and may help to develop interventions to improve the quality of life in the elderly.

In this study, social health status was found to be positively associated with PCS among the elderly, which was supported by previous studies for the association of social health related factors with physical health among the elderly [31-35]. A cross-sectional study conducted in Kuwaitis showed that having children, perception of social support, frequency of contact with kin, and strength of relationships with kin were important modulators of somatic symptoms among the elderly [36]. And a longitudinal study in Japan suggested that interaction between 
environment and multifaceted social relationships had the strongest impact on functional ability for the elderly [37]. Increased social relationships had beneficial effects in fostering the elders' physical and cognitive functions through active participation in social activities and building social networks [38].

Meanwhile, social health status was a positive factor of MCS, which was supported by previous studies for the association of social health related factors with mental health among the elderly [39-43]. The wave three of Nord-Trøndelag Health Study (HUNT3 Study) indicated that lesser psychological distress in the elderly was dependent on better scores on social support [44]; An observational study demonstrated that in the healthy elderly, participating in a social activity could help improve psychological distress [45]. Depression was one of the most prevalent mental disorders in the elderly population and was associated with risk of disability and mortality [46], and several studies have suggested the associations of social support, social participation, and social relationships with depression symptom [47-49].

Perceived environment resource is also an important dimension of social health. The World Report on Aging and Health recommends that decision-makers need to build supportive and enabling environments, which can help people build and maintain capacity (for example, a walkable environment may foster physical activity) [50]. A study in Hong Kong showed that environmental walkability was associated with HR-QOL among older adults [51]. Moreover, some perceived environment resources, such as safety from traffic and street noise were associated with HR-QOL [16]. The changes in the environment around the community may also affect healthrelated quality of life in the elderly.

Additionally, we noticed that participants who lived in the rural region, were females, aged 75 years and older, were not tea drinkers, or had less than 4000 yuan of monthly income, BMI $<18.5 \mathrm{~kg} / \mathrm{m}^{2}$, or chronic conditions with depression symptom were more likely to report lower SF-12 total score. Also, we noticed that monthly income over $3000 \mathrm{CNY}$ was a positive factor of MCS, which was not comparable with a previous study [10]. Possible explanations could be: most of older people in this study were retirees and got money from their children or pension. Consequently, those older people who got more money per month could have less economic hardship and a peaceful life attitude.

Our study had some important strengths. It was the first study that explored the influential factors of HRQOL among the elderly from a perspective of social health status. Moreover, we enrolled a total of 2952 elderly people, which could be considered as a large sample compared with similar studies. Finally, the combination of indicators (PCS, MCS, and SF-12 total score) could improve the meaning of our results. However, our study also had several limitations. Firstly, our study was a cross-sectional study and the causal relationship could not be demonstrated. Secondly, selection bias might not be avoided due to the nonrandomized sampling and relatively low response rate. However, the age and sex distributions of the study population were similar to the Zhejiang elderly population. Finally, although we adjusted for many possible confounders (such as smoking, alcohol drinking, and tea consumption), we lacked information on other potential confounders, such as dietary patterns.

\section{Conclusion}

In summary, to our knowledge, this was the first study to explore the relationship between social health status and HR-QOL among Chinese elderly people. Our results showed that social health status was positively associated with HR-QOL among the elderly in Zhejiang, after adjusting for potential confounding factors. These findings could provide an understanding of how social health status affect HR-QOL of older adults, as well as a new insight into a reference for promoting the HR-QOL among Chinese elderly people.

\section{Supplementary information}

Supplementary information accompanies this paper at https://doi.org/10. 1186/s12955-020-01358-4

\section{Additional file 1.}

Additional file 2: TableS1. The multiple linear regression results of PCS among the elderly. TableS2. The multiple linear regression results of MCS among the elderly. TableS3. The multiple linear regression results of SF-12 total score among the elderly.

\section{Abbreviations}

HR-QOL: Health-related quality of life; SF-12: The 12-item Short-Form Health Survey; SHSE-L: The long-form of the Social Health Scale for the Elderly; PCS: Physical component summary; MCS: Mental component summary; WHO: World health organization; CDC: Centers for Disease Control and Prevention; QoL: Quality of life; SP: Social participation; SS: Social adjustment; BMI: Body mass index; CNY: Chinese yuan; CHD: Coronary heart disease.; GDS: Geriatric Depression Scale; SD: Standard deviation; ANOVA: Analysis of Variance; CI: Confidence interval; VIF: Variance inflation factor; SPSS: Statistical Package for Social Sciences

\section{Acknowledgments}

The authors would like to thank the nurse, clinicians, and management staff in Primary Health Service Center Planning of Kaixuan district and Yiwu county and medical students in the school of medicine, Zhejiang University for their participation and support for this research.

\section{Authors' contributions}

ZBY and KC led the central subject. JML performed the data analyses and led the writing of the manuscript. MYW and ZBY developed the design in consultation with JBW. LQY, FW and ZHX facilitated data collection. XCZ, SJL and YZ pre-processed data. JBW, MJJ and MLT review the manuscript and polished the language. All authors read and approved the final manuscript. 


\section{Funding}

This study was funded by the Ministry of Science and Technology of the people's Republic of China (NO.2015FY111600).

\section{Availability of data and materials}

The datasets generated during and/or analyzed during the current study are not publicly available, but are available from the corresponding author who was an organizer of the study.

\section{Ethics approval and consent to participate}

The medical ethics committee in Zhejiang university school of medicine approved this study. Each participant had signed informed consent before the face-to-face interview.

\section{Consent for publication \\ Not applicable.}

\section{Competing interests}

The authors declare that they have no competing interests.

\section{Author details}

'Department of Epidemiology and Biostatistics, Zhejiang University, School of Medicine, Hangzhou, Zhejiang, China. ${ }^{2}$ Department of Epidemiology and Biostatistics, Cancer Institute, the Second Affiliated Hospital, Zhejiang University School of Medicine, Hangzhou, China. ${ }^{3}$ Department of Epidemiology and Biostatistics, the Children's Hospital, National Clinical Research Center for Child Health, Zhejiang University School of Medicine, Hangzhou, China.

\section{Received: 22 May 2019 Accepted: 8 April 2020}

Published online: 28 April 2020

\section{References}

1. World Health Statistics 2016[http: //apps. who. int/ iris/ bitstream/ 10665/ 206498/ 1/ 9789241565264 eng.pdf?ua=1]. Accessed 11 Jun 2019.

2. Cai Y. China's new demographic reality: learning from the 2010 census. Popul Dev Rev. 2013;39(3):371-96.

3. Centers for Disease Control and Prevention, National center for chronic Disease Prevention and Health Promotion, Division of Adult and Community Health. Measuring healthy days: Population assessment of health-related quality of life. Atlanta: CDC; 2000. p. 4-6. http://www.cdc.gov/ hrqol/pdfs/mhd.pdf. Accessed 1 Jan 2019.

4. Mayo NE. Dictionary of Quality of Life and Health Outcomes Measurement In: International Society for Quality of Life Research. 1st ed; 2015. p. 3.

5. Hagen KA, Hilsen M, Kallander EK, Ruud T. Health-related quality of life (HRQoL) in children of ill or substance abusing parents: examining factor structure and sub-group differences. Qual Life Res. 2019;28(4):1063-73.

6. Balboa-Castillo T, Leon-Munoz LM, Graciani A, Rodriguez-Artalejo F, GuallarCastillon P. Longitudinal association of physical activity and sedentary behavior during leisure time with health-related quality of life in 2community-dwelling older adults. Health Qual Life Outcomes. 2011;9(47):1-10.

7. Hong S, Jeong H, Heo Y, Chun H, Park J, Kim D. Factors associated with health-related quality of life in Korean older workers. Ann Occup Environ Med. 2015;27(25):1-11

8. Bayan-Bravo A, Perez-Tasigchana RF, Sayon-Orea C, Martinez-Gomez D, Lopez-Garcia E, Rodriguez-Artalejo F, Guallar-Castillon P. Combined Impact of Traditional and Non-Traditional Healthy Behaviors on Health-Related Quality of Life: A Prospective Study in Older Adults. PLoS One. 2017;12(1): e0170513.

9. Kim J, Choi Y, Park S, Cho KH, Ju YJ, Park EC. The impact of living arrangements on quality of life among Korean elderly: findings from the Korean longitudinal study of aging (2006-2012). Qual Life Res. 2017;26(5): 1303-14.

10. Ma X, McGhee SM. A cross-sectional study on socioeconomic status and health-related quality of life among elderly Chinese. BMJ Open. 2013;3(2):1-9.

11. Sun W, Aodeng S, Tanimoto Y, Watanabe M, Han J, Wang B, Yu L, Kono K. Quality of life (QOL) of the community-dwelling elderly and associated factors: a population-based study in urban areas of China. Arch Geronto Geriatr. 2015;60(2):311-6.
12. Huber M, Knottnerus JA, Green L, van der Horst H, Jadad AR, Kromhout D, Leonard B, Lorig K, Loureiro MI, van der Meer JW, Schnabel P, Smith R, van Weel C, Smid H. How should we define health? BMJ. 2011;343:1-3.

13. McDowell I. Measuring health: a guide to rating scales and questionnaires. 3rd ed. New York: Oxford University Press; 2006.

14. Russell RD. Social health: an attempt to clarify this dimension of well-being. Int J Health Educ. 1973;16:74-82.

15. Bao C, Yu Z, Yin X, Chen Z, Meng L, Yang W, Chen X, Jin M, Wang J, Tang $M$, Chen K. The development of the social health scale for the elderly. Health Qual Life Outcomes. 2018;16(67):1-14.

16. Parra DC, Gomez LF, Sarmiento OL, Buchner D, Brownson R, Schimd T, Gomez V, Lobelo F. Perceived and objective neighborhood environment attributes and health related quality of life among the elderly in Bogota, Colombia. Soc Sci Med. 2010;70(7):1070-6.

17. Sun Y, Zhang D, Yang Y, Wu M, Xie H, Zhang J, Jia J, Su Y. Social support moderates the effects of self-esteem and depression on quality of life among Chinese rural elderly in nursing homes. Arch Psychiatr Nurs. 2017; 31(2):197-204

18. Kim J, Lee JE. Social support and health-related quality of life among elderly individuals living alone in South Korea: a cross-sectional study. J Nurs Res. 2018;26(5):316-23.

19. Lee H, Cho SH, Kim JH, Kim YK, Choo HI. Influence of self efficacy, social support and sense of community on health-related quality of life for middle-aged and elderly residents living in a rural community. J Korean Acad Nurs. 2014:44(6):608-16.

20. Wu M, Yang Y, Zhang D, Zhao X, Sun Y, Xie H, Jia J, Su Y, Li Y. Association between social support and health-related quality of life among Chinese rural elders in nursing homes: the mediating role of resilience. Qual Life Res. 2018;27(3):783-92.

21. Choi Y, Lee KS, Shin J, Kwon JA, Park EC. Effects of a change in social activity on quality of life among middle-aged and elderly Koreans: analysis of the Korean longitudinal study of aging (2006-2012). Geriatr Gerontol Int. 2017;17(1):132-41.

22. Gobbens RJJ, van Assen M. Associations of environmental factors with quality of life in older adults. Gerontologist. 2018;58(1):101-10.

23. Hembling DW. Rapid conversion of adolescent Mmpi raw scores to T scores using the Hp-67 programmable calculator. J Clin Psychol. 1984;40:149-56.

24. Shou J, Ren L, Wang H, Yan F, Cao X, Wang H, Wang Z, Zhu S, Liu Y. Reliability and validity of 12-item short-form health survey (SF-12) for the health status of Chinese community elderly population in Xujiahui district of Shanghai. Aging Clin Exp Res. 2016;28(2):339-46.

25. Ware JE, Kosinski M, Keller SD. SF-12: how to score the SF-12 physical and mental health summary scales. 2nd ed. Boston: The Health Institute, New England Medical Center; 1995.

26. Barnett CT, Vanicek N, Polman RC. Temporal adaptations in generic and population-specific quality of life and falls efficacy in men with recent lower-limb amputations. J Rehabil Res Dev. 2013;50(3):437-48.

27. Md Yusop NB, Yoke Mun C, Shariff ZM, Beng HC. Factors associated with quality of life among hemodialysis patients in Malaysia. PLoS One. 2013; $8(12): 1-11$.

28. Pekmezovic T, Jecmenica-Lukic M, Petrovic I, Spica V, Tomic A, Kostic VS Quality of life in patients with progressive supranuclear palsy: one-year follow-up. J Neurol. 2015;262(9):2042-8.

29. Song T, Ding YW, Sun Y, He YN, Qi DJ, Wu Y, Wu B, Lang L, Yu K, Zhao X, Zhu LL, Wang S, Yu XS. A population-based study on health-related quality of life among urban community residents in Shenyang, Northeast of China. BMC Public Health. 2015;15(921):1-12.

30. Wang JB, Huang QC, Hu SC, Zheng PW, Shen P, Li D, Lu HC, Gao X, Lin HB, Chen K. Baseline and longitudinal change in blood pressure and mortality in a Chinese cohort. J Epidemiol Community Health. 2018;72:1083-90.

31. Gadalla TM. Sense of mastery, social support, and health in elderly Canadians. J Aging Health. 2009;21(4):581-95.

32. Jang PO, So HS. Model development of an elderly health promotion center: the effect of a social support program at a community health center. Taehan Kanho Hakhoe Chi. 2004;34(5):781-90.

33. Kishi $R$, Horikawa N. Role of the social support network which influences age of death and physical function of elderly people: study of trends in and outside of Japan and future problems. Nihon Koshu Eisei Zasshi. 2004;51(2): 79-93.

34. Lopez-Tellez A, Rio Ruiz J, Molinero Torres F, Fernandez Maldonado I, Martinez Zaragoza I, Prados TP. Effectiveness of a social-physical activity 
intervention program in an elderly social risk population. Semergen. 2012; 38(3):137-44.

35. Xie H, Peng W, Yang Y, Zhang D, Sun Y, Wu M, Zhang J, Jia J, Su Y. Social support as a mediator of physical disability and depressive symptoms in Chinese elderly. Arch Psychiatr Nurs. 2018;32(2):256-62.

36. Al-Kandari YY, Crews DE. Social support and health among elderly Kuwaitis. J Biosoc Sci. 2014;46(4):518-30.

37. Watanabe K, Tanaka E, Watanabe T, Chen W, Wu B, Ito S, Okumura R, Anme T. Association between the older adults' social relationships and functional status in Japan. Geriatr Gerontol Int. 2017;17(10):1522-6.

38. Ali T, Nilsson CJ, Weuve J, Rajan KB. Mendes de Leon C F. effects of social network diversity on mortality, cognition and physical function in the elderly: a longitudinal analysis of the Chicago health and aging project (CHAP). J Epidemiol Community Health. 2018;72(11):990-6.

39. Cornman JC, Goldman N, Glei DA, Weinstein M, Chang MC. Social ties and perceived support: two dimensions of social relationships and health among the elderly in Taiwan. J Aging Health. 2003;15(4):616-44.

40. Revicki DA, Mitchell JP. Strain, social support, and mental health in rural elderly individuals. J Gerontol. 1990;45(6):S267-74.

41. Villeneuve L, Lebel P, Lambert J. Stress and social support in relation to psychological distress in community-residing elderly persons in Montreal. Can J Public Health. 1992:83(5):354-6.

42. Lee JE, Kahana B, Kahana E. Social support and cognitive functioning as resources for elderly persons with chronic arthritis pain. Aging Ment Health. 2016;20(4):370-9

43. Santini ZI, Fiori KL, Feeney J, Tyrovolas S, Haro JM, Koyanagi A. Social relationships, loneliness, and mental health among older men and women in Ireland: a prospective community-based study. J Affect Disord. 2016;204: 59-69.

44. Gronning K, Espnes GA, Nguyen C, Rodrigues AMF, Gregorio MJ, Sousa R, Canhao H, Andre B. Psychological distress in elderly people is associated with diet, wellbeing, health status, social support and physical functioninga HUNT3 study. BMC Geriatr. 2018;18(205):1-8.

45. Owari Y, Miyatake N, Kataoka H. Relationship between social participation, physical activity and psychological distress in apparently healthy elderly people: a pilot study. Acta Med Okayama. 2018;72(1):31-7.

46. Sozeri-Varma G. Depression in the elderly: clinical features and risk factors. Aging Dis. 2012;3(6):465-71.

47. Chou KL, Chi I. Reciprocal relationship between social support and depressive symptoms among Chinese elderly. Aging Ment Health. 2003;7(3): 224-31.

48. Hao G, Bishwajit G, Tang S, Nie C, Ji L, Huang R. Social participation and perceived depression among elderly population in South Africa. Clin Interv Aging. 2017;12:971-6.

49. Mechakra-Tahiri S, Zunzunegui MV, Preville M, Dube M. Social relationships and depression among people 65 years and over living in rural and urban areas of Quebec. Int J Geriatr Psychiatry. 2009;24(11):1226-36.

50. Beard JR, Officer AM, Cassels AK. The world report on ageing and health. Gerontologist. 2016;56(S2):S163-6

51. Zhao Y, Chung PK. Neighborhood environment walkability and healthrelated quality of life among older adults in Hong Kong. Arch Gerontol Geriatr. 2017;73:182-6.

\section{Publisher's Note}

Springer Nature remains neutral with regard to jurisdictional claims in published maps and institutional affiliations.

Ready to submit your research? Choose BMC and benefit from:

- fast, convenient online submission

- thorough peer review by experienced researchers in your field

- rapid publication on acceptance

- support for research data, including large and complex data types

- gold Open Access which fosters wider collaboration and increased citations

- maximum visibility for your research: over $100 \mathrm{M}$ website views per year

At $\mathrm{BMC}$, research is always in progress.

Learn more biomedcentral.com/submissions 